\title{
Peptide radiopharmaceuticals for diagnosis and therapy
}

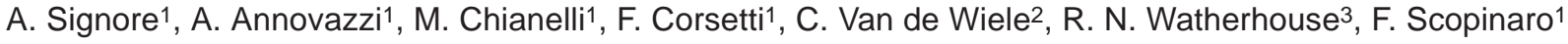 \\ 1 Nuclear Medicine Unit, Department of Clinical Science, Policlinico Umberto I, University "La Sapienza", 00161 Rome, Italy \\ 2 Division of Nuclear Medicine, University Hospital Ghent, Belgium \\ 3 Department of Psychiatry, Columbia University, New York, USA \\ Published online: 26 September 2001 \\ (c) Springer-Verlag 2001
}

Eur J Nucl Med (2001) 28:1737

DOI 10.1007/s00259-001-0663-7

\section{Eur J Nucl Med (2001) 28:1555-1565}

It has come to the authors' attention that two paragraphs were not optimally placed within our occasional survey.

The single-sentence paragraph "Insulin-like growth factor-1 (IGF-I) [41] has also shown good uptake on receptor-overexpressing tumour cells." within the section "G-protein-coupled receptor radioligands" should in fact have been included in the third paragraph within the sec- tion "Tyrosine kinase receptor radioligands". That paragraph should thus have commenced "Insulin-like growth factor-1 (IGF-I) [41] has also shown good uptake on receptor-overexpressing tumour cells. des(1-3)IGF-I, which lacks the N-terminal tripeptide Gly-Pro-Glu...."

The subsequent paragraph within the section "G-protein-coupled receptor radioligands", commencing "The integrin-binding peptide RDG (Arg-Gly-Asp) and related sequences represent a novel class of peptides able to bind to the v3 and v5 integrins...", should have appeared as the first paragraph in the section "Other peptide radiopharmaceuticals".

We apologise for any confusion that may have been caused.

The online version of the original article can be found at http://dx.doi.org/10.1007/s002590100583

\section{A. Signore (区)}

Nuclear Medicine Unit, Department of Clinical Science,

Policlinico Umberto I, University "La Sapienza”,

00161 Rome, Italy

e-mail: alberto.signore@uniroma1.it

Tel.: +39-06-49970518, Fax: +39-06-49970524 